ORIGINAL ARTICLE

\title{
Comparison of visceral fat mass measurement by dual-X-ray absorptiometry and magnetic resonance imaging in a multiethnic cohort: the Dallas Heart Study
}

\author{
IJ Neeland ${ }^{1}$, SM Grundy ${ }^{1,2,3}, \mathrm{X} \mathrm{Li}^{4}, \mathrm{~B}$ Adams-Huet ${ }^{1,4}$ and GL Vega ${ }^{2,3,5}$
}

\begin{abstract}
BACKGROUND/OBJECTIVES: Visceral adipose tissue (VAT) mass, a risk factor for cardiometabolic complications of obesity, is usually measured by magnetic resonance imaging (MRI) but this method is not practical in a clinical setting. In contrast, measurement of VAT by dual-x-ray absorptiometry (DXA) appears to circumvent the limitations of MRI. In this study, we compared measurements of VAT mass by MRI and DXA in the large, multiethnic cohort of the Dallas Heart Study (DHS).

SUBJECTS/METHODS: About $2689 \mathrm{DHS}$ participants underwent paired measurement of VAT by MRI and DXA. Sex-stratified analyses were performed to evaluate the correlation and agreement between DXA and MRI. Model validation was performed using bootstrapping and inter-reader variability was assessed.

RESULTS: Mean age of the cohort was 44 years, with $55 \%$ female, $48 \%$ Black and $75 \%$ overweight/obese participants. Regression analysis showed a linear relationship between DXA and MRI with $R^{2}=0.82$ (95\% confidence interval (CI) $\left.0.81-0.84\right)$ for females and $R^{2}=0.86(95 \% \mathrm{Cl} 0.85-0.88)$ for males. Mean difference between methods was $0.01 \mathrm{~kg}$ for females and $0.09 \mathrm{~kg}$ for males. Bland-Altman analysis showed that DXA tended to modestly underestimate VAT compared with MRI at lower VAT levels and overestimate it compared with MRI at higher VAT levels. Results were consistent in analyses stratified by race, body mass index status, waist girth and body fat. Inter-individual reader correlation among 50 randomly selected scans was excellent (inter-class correlation coefficient $=0.997$ ).
\end{abstract}

CONCLUSIONS: VAT mass quantification by DXA was both accurate and valid among a large, multiethnic cohort within a wide range of body fatness. Further studies including repeat assessments over time will help determine its long-term applicability.

Nutrition \& Diabetes (2016) 6, e221; doi:10.1038/nutd.2016.28; published online 18 July 2016

\section{INTRODUCTION}

Visceral adipose tissue (VAT) imparts risk for type 2 diabetes, ${ }^{1}$ hypertension ${ }^{2}$ and cardiovascular disease. ${ }^{3,4}$ Moreover, reduction in VAT may potentially explain some of the improvements in cardiovascular disease risk seen with lifestyle, ${ }^{5}$ medical $^{6}$ and surgical ${ }^{7}$ weight loss interventions. Although VAT can be accurately measured using dedicated techniques, such as magnetic resonance (MRI) and computerized tomography (CT) imaging, implementation of these modalities remain limited in both clinical practice and research investigation due to high cost, prolonged scan time (with MRI) and significant radiation exposure (with CT).

Estimation of VAT mass is now possible during the measurement of body composition using dual-x-ray absorptiometry (DXA). This method uses the differential attenuation of X-ray beams at two separate energies to calculate the soft tissue composition in a scanned region of interest and can be used to measure both whole-body and regional distribution of fat and lean mass. ${ }^{8}$ The effective radiation dose incurred during DXA scanning is relatively $\operatorname{low}^{9}(\sim 1.5 \mathrm{mrem})$ and the scan time is of short duration compared with MRI or CT, making DXA a simpler, generally safer and faster technique than other modalities for serial measurements of body composition. Several studies that have examined the accuracy and precision of DXA methods to measure VAT mass report strong correlations $(r>0.9)$ with expert manual or software-based measurements with CT imaging. ${ }^{10-13}$ However, large, multiethnic populations with high proportions of both sexes have not been studied with DXA compared with MRI. Thus, we aimed to compare VAT mass quantified by paired MRI and DXA measurements in the Dallas Heart Study (DHS) population. We also sought to identify important sources of variability and limitations related to DXA VAT measurement in order to substantiate its use for future clinical and research applications.

\section{METHODS}

Study population and variable definitions

The DHS is a multiethnic, probability-based, population cohort study of Dallas County adults with deliberate oversampling of African-Americans. Detailed methods of the DHS have been described previously. ${ }^{14}$ Briefly, between 2000 and 2002, 2693 subjects completed three DHS visits, including a detailed in-home survey, laboratory testing, and DXA and MRI imaging scans. Data on body composition and regional fat distribution measured by DXA and MRI have been published previously for this cohort. ${ }^{15}$ In the current study, the advanced version of the APEX software (Hologic Inc., Bedford, MA, USA) was employed to re-analyze the DXA images previously obtained and to generate VAT mass estimates to

\footnotetext{
'Department of Internal Medicine, University of Texas Southwestern Medical Center, Dallas, TX, USA; ${ }^{2}$ Dallas VA North Texas Health Care System, Dallas, TX, USA; ${ }^{3}$ Center for Human Nutrition, University of Texas Southwestern Medical Center, Dallas, TX, USA; ${ }^{4}$ Department of Clinical Sciences, University of Texas Southwestern Medical Center, Dallas, TX, USA and ${ }^{5}$ Department of Clinical Nutrition, University of Texas Southwestern Medical Center, Dallas, TX, USA. Correspondence: Dr IJ Neeland, Department of Internal Medicine, University of Texas Southwestern Medical Center, 5323 Harry Hines Blvd, Dallas, TX 75390-8830, USA. or Dr GL Vega, Department of Clinical Nutrition, University of Texas Southwestern Medical Center, 5323 Harry Hines Blvd, Dallas, TX 75390-9052, USA.

E-mail: ian.neeland@utsouthwestern.edu or gloria.vega@utsouthwestern.edu

Received 23 March 2016; revised 2 June 2016; accepted 19 June 2016
} 
compare with previously published MRI VAT mass. For the present analyses, participants with irregular MRI or DXA data were excluded $(n=4$, one participant with negative VAT by MRI and three participants with exceedingly discordant DXA VAT data), yielding a final sample size of 2689. Age, sex, race/ethnicity, history of cardiovascular disease and smoking status were self-reported. Definitions for hypertension, diabetes, low highdensity lipoprotein cholesterol and metabolic syndrome have been previously described using conventional clinical definitions. ${ }^{16,17}$ Weight and height were measured using standard scales and body mass index (BMI) was calculated as weight in kilograms divided by height in meters squared; normal weight was defined as a $\mathrm{BMl}<25 \mathrm{~kg} \mathrm{~m}^{-2}$. Waist circumference was measured $1 \mathrm{~cm}$ above the iliac crest and hip circumference at the widest circumference of the buttocks at the area of the greater trochanters. High waist girth was defined as $\geqslant 88 \mathrm{~cm}$ for females and $\geqslant 102 \mathrm{~cm}$ for males. ${ }^{17}$ Participants provided written informed consent, and the protocol was approved by the Institutional Review Board of the University of Texas Southwestern Medical Center.

\section{MRI measurements}

Subjects were imaged by a 1.5 Tesla MRI scanner (Intera, Philips Medical Systems, Best, The Netherlands) using a prospectively designed and validated method of fat mass prediction from a single MRI slice at the L2-L3 intervertebral level. ${ }^{18}$ Abdominal adipose tissue was separated into VAT (intraperitoneal+retroperitoneal fat) and subcutaneous adipose tissue (SAT) compartments by manually circumscribing contours using anatomical landmarks as detailed previously. ${ }^{15}$ Fat volumes were converted to mass using $0.9196 \mathrm{~kg} \mathrm{I}^{-1}$ as the density of triglyceride in adipose tissue. Single-slice measurement of SAT and VAT fat mass at this intervertebral level has been shown to be highly concordant with total abdominal fat mass measured at all intervertebral levels $\left(R^{2}=0.85-0.96\right){ }^{18}$

\section{DXA measurements}

Whole-body composition analysis was performed with a Discovery W DXA scanner (Hologic Inc.), as detailed previously ${ }^{15}$ and images were re-analyzed with APEX software version 13.4 .2 for the present report. This software enables estimation of VAT mass at the L4-L5 region. The methodology for DXA VAT measurement has been described previously. ${ }^{11}$ Briefly, the lateral abdominal SAT seen in the DXA image was used to determine the anterior and posterior abdominal SAT, allowing VAT to be estimated from the total abdominal fat measured (total abdominal fat - total abdominal SAT=VAT, expressed in $\mathrm{kg}$ in the L4-L5 slice). As MRI VAT mass data are expressed as total mass (in $\mathrm{kg}$ ) spanning the L1-L5 region, scaling factors were derived for the estimation of total VAT mass from L1-L5 measured by DXA as detailed in the results below. Low and high body fat were defined as $<35 \%$ and $\geqslant 35 \%$ total body fat for females and $<25 \%$ and $\geqslant 25 \%$ total body fat for males, respectively.

\section{Statistical analysis}

All analyses were a priori stratified by sex. Histograms describing the distribution of VAT measured by DXA and MRI were constructed. VAT measured by DXA and MRI among groups stratified by race, BMI status, waist girth and percent body fat were summarized as mean (s.d.). Trends across DXA VAT quartiles were analyzed by the Jonckheere-Terpstra test for continuous variables and the Cochran-Armitage test for categorical variables. Correlation plots between DXA VAT and MRI VAT with $95 \%$ prediction limits were generated and regression equations with best-fit line and $R^{2}$ with s.e. of the estimate values were calculated using ordinary least squares regression. Outliers were assessed to determine their influence on the correlation. Bland-Altman analysis using regressionbased limits of agreement ${ }^{19}$ was performed to assess the bias and limits of agreement between DXA VAT and MRI VAT measurements. A regressionbased approach was used because standard Bland-Altman analysis demonstrated heteroscedasticity and non-uniform differences across the range of measurements (that is, an increase in variability of the differences as the magnitude of the VAT measurement increased). Validation of the DXA VAT measurement using MRI VAT as the primary standard was performed using bootstrapping methods as described by Harrell et al. ${ }^{20}$ This technique may be superior to cross-validation techniques and is a recommended method for estimation of internal validity of a predictive regression model in obesity and nutrition research, as recently reviewed. ${ }^{21}$ Weighted kappa agreement coefficients were computed to determine the likelihood that individuals in the highest quartile of VAT by MRI would be classified in the highest quartiles of VAT by DXA. The inter-class correlation coefficient was determined by comparing DXA VAT values as measured by two independent observers for 50 randomly selected scans. Internal validity of the DXA VAT measurements was assessed by evaluating the relationship of DXA VAT quartiles with cardiometabolic risk factors. For all statistical testing, a 2 -sided $P$-value $<0.05$ was considered statistically significant. All statistical analyses were performed using SAS version 9.4 software (SAS Institute, Cary, NC, USA).

\section{RESULTS}

Table 1 describes the characteristics of the study population; mean age was 44 years, $55 \%$ were female, $48 \%$ were Black and $75 \%$ were overweight or obese. A subset of this population who did not have type 2 diabetes mellitus was selected to determine a scaling factor for conversion of DXA VAT fat mass in L4-L5 to total VAT mass in L1-L5. Plots of DXA VAT fat mass $(\mathrm{kg})$ at L4-L5 vs MRI VAT mass $(\mathrm{kg})$ at L1-L5 were constructed separately for females and males (Figure 1). There was a strong linear association between these two measurements $\left(R^{2}=0.82, P<0.001\right.$ for females and $R^{2}=0.87, P<0.001$ for males). The ratio of MRI VAT mass to DXA VAT mass was calculated for each sex and racial/ ethnic group (Table 2). An average scaling factor (ratio) of 2.77 was calculated for females and 3.69 for males. These factors were subsequently used to calculate the total DXA VAT fat mass of L1L5 and the results were compared with the MRI VAT fat mass for the entire DHS population. Total VAT mass was relatively normally distributed among both females and males, with slight rightward skewness, and DXA- and MRI-measured VAT mass appeared to have similarly shaped distributions among both sexes (data not shown). The range of DXA total VAT mass was $0.03-5.22 \mathrm{~kg}$ among females and $0.42-7.49 \mathrm{~kg}$ among males.

The coefficients of determination $\left(R^{2}\right)$ and $95 \%$ confidence limits for linear regression of MRI on DXA VAT mass stratified by sex and race are shown in Table 3 and the correlation plots with 95\% limits of prediction between DXA-estimated and MRImeasured VAT mass by sex are shown in Figure 2. The $R^{2}$ for linear regression of MRI on DXA VAT mass was 0.82 for females and 0.86 for males. The best-fit line describing the relationship

\begin{tabular}{|c|c|c|}
\hline \multirow[t]{2}{*}{ Baseline characteristics } & \multicolumn{2}{|c|}{ Mean (s.d.) } \\
\hline & $\begin{array}{c}\text { Female } \\
(\mathrm{n}=1477)\end{array}$ & $\begin{array}{c}\text { Male } \\
(\mathrm{n}=1212)\end{array}$ \\
\hline Age (years) & $44.5(10.0)$ & $44.3(9.7)$ \\
\hline \multicolumn{3}{|l|}{ Race (\%) } \\
\hline Black & 50.2 & 45.6 \\
\hline White & 30.2 & 34.9 \\
\hline Hispanic & 18.3 & 16.3 \\
\hline Weight (kg) & $83.3(18.7)$ & $86.9(16.7)$ \\
\hline Body mass index (BMI) $\left(\mathrm{kg} \mathrm{m}^{-2}\right)$ & $30.8(7.3)$ & $28.4(4.9)$ \\
\hline $\mathrm{BMI} \geqslant 25(\%)$ & 76.6 & 74.3 \\
\hline Waist circumference $(\mathrm{cm})$ & $95.9(16.2)$ & $98.9(12.8)$ \\
\hline High waist girth ${ }^{\mathrm{a}}(\%)$ & 66.3 & 39.9 \\
\hline Total fat mass $(\mathrm{kg})$ & $33.8(12.4)$ & $24.5(8.9)$ \\
\hline Total body fat (\%) & $41.6(6.5)$ & $27.9(6.2)$ \\
\hline Total lean mass $(\mathrm{kg})$ & $45.2(8.1)$ & $61.0(8.9)$ \\
\hline Hypertension (\%) & 31.9 & 28.6 \\
\hline Diabetes mellitus (\%) & 10.2 & 10.2 \\
\hline Metabolic syndrome (\%) & 36.6 & 29.2 \\
\hline Smokers (\%) & 23.7 & 33.2 \\
\hline
\end{tabular}

${ }^{a}$ High waist girth defined as $\geqslant 88 \mathrm{~cm}$ for females and $\geqslant 102 \mathrm{~cm}$ for males. Data are reported as mean (s.d.) or proportion (\%) as appropriate. 
between MRI and DXA VAT was $\operatorname{VAT}_{(\mathrm{MRI})}(\mathrm{kg})=0.76 \times \mathrm{VAT}_{(\mathrm{DXA})}$ $(\mathrm{kg})+0.44$ for females and $\operatorname{VAT}_{(\mathrm{MRI})}(\mathrm{kg})=0.81 \times \operatorname{VAT}_{(\mathrm{DXA})}(\mathrm{kg})+$ 0.41 for males. Correlation plots between DXA-estimated and MRImeasured VAT for females and males separated by race showed similar results (Supplementary Figure S1). Quadratic and (subsequently) cubic terms were included in the regression analysis to determine whether alternative regression strategies resulted in a better fit for the relationship between DXA and MRI VAT. Both quadratic and cubic terms were not significant for females; for males, both terms were significant $\left(R^{2}=0.87\right.$ for quadratic and
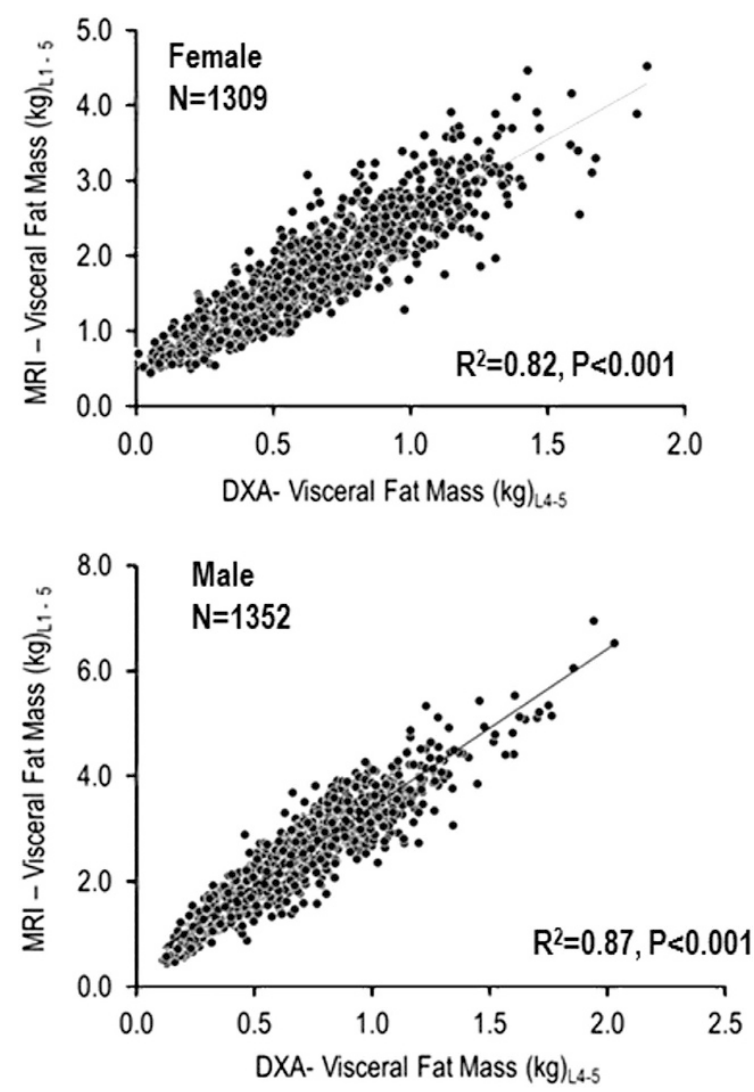

Figure 1. Plots of DXA VAT mass at L4-L5 vs MRI VAT mass from L1-L5 used to derive scaling factors for the estimation of total VAT mass by DXA. Plots of VAT mass estimated by DXA $(\mathrm{kg})$ at intervertebral L4-L5 vs MRI-estimated VAT mass $(\mathrm{kg})$ at the beginning of L1 and end of L5 vertebrae in a subgroup of nondiabetic females and males.

Table 2. Derivation of scaling factors for estimation of total visceral fat mass by DXA

\begin{tabular}{|c|c|c|c|c|c|}
\hline \multirow{2}{*}{$\begin{array}{l}\text { Study } \\
\text { group }\end{array}$} & \multirow[t]{2}{*}{ Number } & \multicolumn{2}{|c|}{ Anatomical region } & \multirow{2}{*}{$\begin{array}{l}\text { Scaling factor } \\
\text { (ratio) }\end{array}$} & \multirow{2}{*}{$\begin{array}{l}\text { Mean (s.d.) } \\
\text { scaling factor }\end{array}$} \\
\hline & & $\begin{array}{l}\text { DXA } \\
\text { L4-L5 }\end{array}$ & $\begin{array}{c}M R I \\
L 1-L 5\end{array}$ & & \\
\hline \multicolumn{6}{|c|}{ Visceral fat mass, $\mathrm{kg}$ (s.d.) } \\
\hline Female & & & & & \\
\hline Black & 647 & $0.63(0.30)$ & $1.72(0.67)$ & 2.70 & \multirow[t]{3}{*}{$2.77(0.06)$} \\
\hline White & 422 & $0.62(0.33)$ & $1.76(0.74)$ & 2.80 & \\
\hline Hispanic & 240 & $0.67(0.28)$ & $1.89(0.67)$ & 2.80 & \\
\hline \multicolumn{6}{|l|}{ Male } \\
\hline Black & 479 & $0.59(0.29)$ & $2.11(0.91)$ & 3.70 & \multirow{3}{*}{$3.69(0.07)$} \\
\hline White & 398 & $0.76(0.32)$ & $2.74(1.06)$ & 3.61 & \\
\hline Hispanic & 172 & $0.72(0.25)$ & $2.70(0.80)$ & 3.75 & \\
\hline
\end{tabular}

Abbreviations: DXA, dual-x-ray absorptiometry; MRI, magnetic resonance imaging.
Table 3. Coefficients of determination $\left(R^{2}\right)$ and $95 \%$ confidence limits for linear regression of MRI on DXA VAT mass $(\mathrm{kg})$ stratified by sex and race

\begin{tabular}{lcc}
\hline Subgroup & $\begin{array}{c}\text { Number of } \\
\text { participants }\end{array}$ & $\mathrm{R}^{2}(95 \% \mathrm{Cl})$ \\
\hline Female & 1477 & $0.82(0.81-0.84)$ \\
Black & 741 & $0.79(0.76-0.82)$ \\
White & 446 & $0.87(0.85-0.89)$ \\
Hispanic & 270 & $0.82(0.75-0.87)$ \\
Male & 1212 & $0.86(0.85-0.88)$ \\
Black & 553 & $0.85(0.82-0.88)$ \\
White & 423 & $0.88(0.85-0.90)$ \\
Hispanic & 198 & $0.81(0.74-0.86)$ \\
\hline
\end{tabular}

Abbreviations: $\mathrm{Cl}$, confidence interval; DXA, dual-x-ray absorptiometry; $\mathrm{MRI}$, magnetic resonance imaging; VAT, visceral adipose tissue. $R^{2}$ indicates the coefficient of determination for the regression equation.

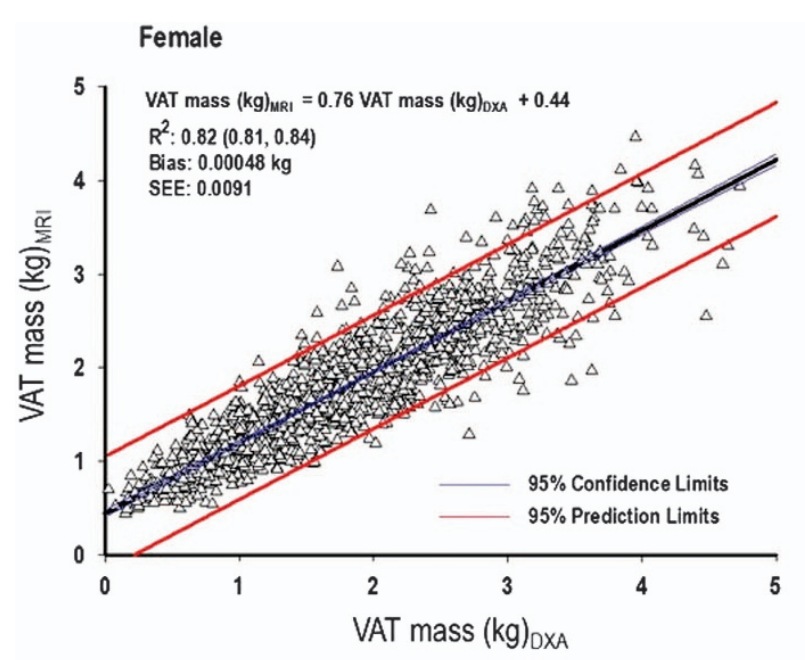

Male

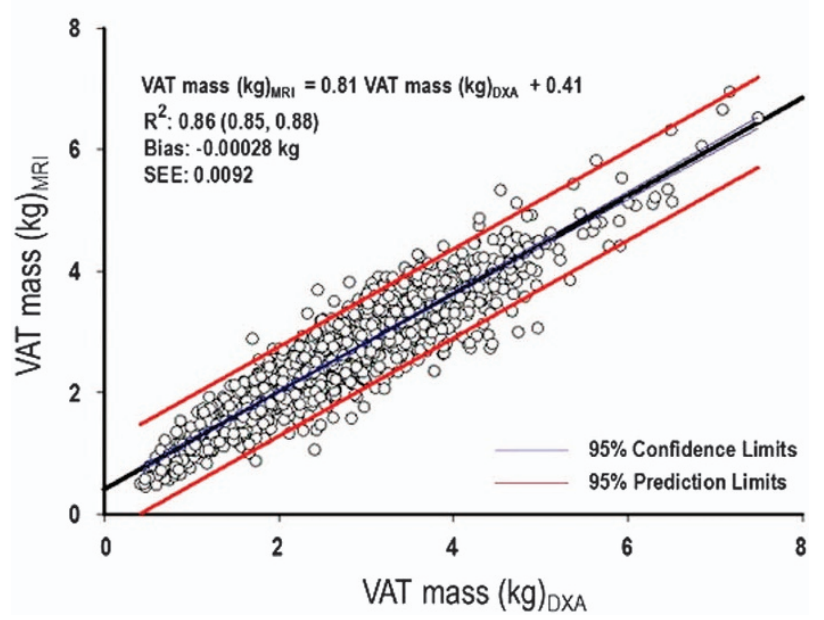

Figure 2. Scatterplots of VAT mass measured by DXA and MRI. Comparison of VAT mass $(\mathrm{kg})$ estimated by DXA with VAT measured by MRI $(\mathrm{kg}) . R^{2}$ indicates the coefficient of determination for the regression equation. $95 \%$ confidence limits of the regression line are in blue; $95 \%$ prediction limits of the correlation are in red. SEE, standard error of the estimate. 
$R^{2}=0.87$ for cubic, $P<0.0001$ for both), but improved negligibly on the overall model fit. Visual inspection of the scatterplots showed that the deviation from a linear relationship occurred primarily at the extremes of VAT measurement in relatively few participants (Supplementary Figure S2). Outliers analysis demonstrated that the relationship between DXA-estimated and MRImeasured VAT was insensitive to inclusion or exclusion of outliers.

Mean (s.d.), mean difference and 95\% limits of agreement for DXA VAT values compared with MRI VAT measurements across subgroups stratified by sex, race and waist girth are shown in Table 4. Mean differences between DXA and MRI VAT were very small in magnitude among both females and males and across racial groups. Although the magnitude of absolute differences were very small, DXA VAT appeared to slightly underestimate MRI VAT among normal weight compared with overweight/obese individuals defined by either waist girth (Table 4), BMI or total percent body fat (Supplementary Table S1), especially among females. Slight overestimation by MRI VAT was noted in the overweight/obese category, especially among males (Table 4 and Supplementary Table S1). Bland-Altman analysis characterizing the agreement between DXA and MRI VAT measurements are presented for females and males in Figure 3. In general, there was an increase in variability of the differences, as the magnitude of the VAT measurement increased. DXA tended to modestly underestimate VAT compared with MRI at lower VAT levels and overestimate it compared with MRI at higher levels. At lower VAT levels where most of the data points were centered, the regression-based limits of agreement were relatively narrow, whereas at higher VAT levels where there were less data points and more variability, the limits of agreement were wider. Similar trends were seen in the Bland-Altman analyses stratified by race for both females and males (data not shown).
Five-hundred bootstrapping repetitions were performed to determine unbiased estimates of the accuracy of the $R^{2}$ resulting from the linear regression of MRI on DXA VAT. The $95 \%$ confidence interval for the $R^{2}$ for females was $0.81-0.84$ and for males it was $0.85-0.88$, suggesting very good validity with relatively low variance in the correlation between MRI and DXA VAT. Weighted kappa agreement coefficients were computed to determine the likelihood that individuals in the highest quartile of VAT by MRI would be classified in the highest quartile of VAT by DXA. The weighted kappa coefficient and 95\% confidence interval for males was $0.76(0.74-0.78)$ and for females it was $0.74(0.72-$ 0.77 ), indicating substantial agreement between methods. ${ }^{22}$ Results were similar for each subgroup by sex and race (Supplementary Table S2). The inter-class correlation coefficient for agreement between two separate readers among 50 randomly selected scans was 0.997 (95\% confidence interval 0.995-0.998) using the random effects method, demonstrating excellent interindividual reader correlation with negligible variability. Increasing DXA VAT quartiles were positively associated with age, prevalent diabetes and metabolic syndrome, and BMI, consistent with prior observations and generally confirming internal validity of the measurement (Table 5).

\section{DISCUSSION}

To our knowledge, this is the largest study to date to evaluate and validate a novel DXA method of VAT quantification in a large, multiethnic cohort and the first such report to validate the DXA VAT method in comparison with MRI as the primary standard. Our results showed a strong agreement between DXA and MRI VAT across subgroups of sex, race and a wide range of BMls, waist girth and percent body fat. DXA appeared to slightly underestimate

Table 4. Comparison of mean visceral fat mass $(\mathrm{kg})$ measured by DXA and MRI

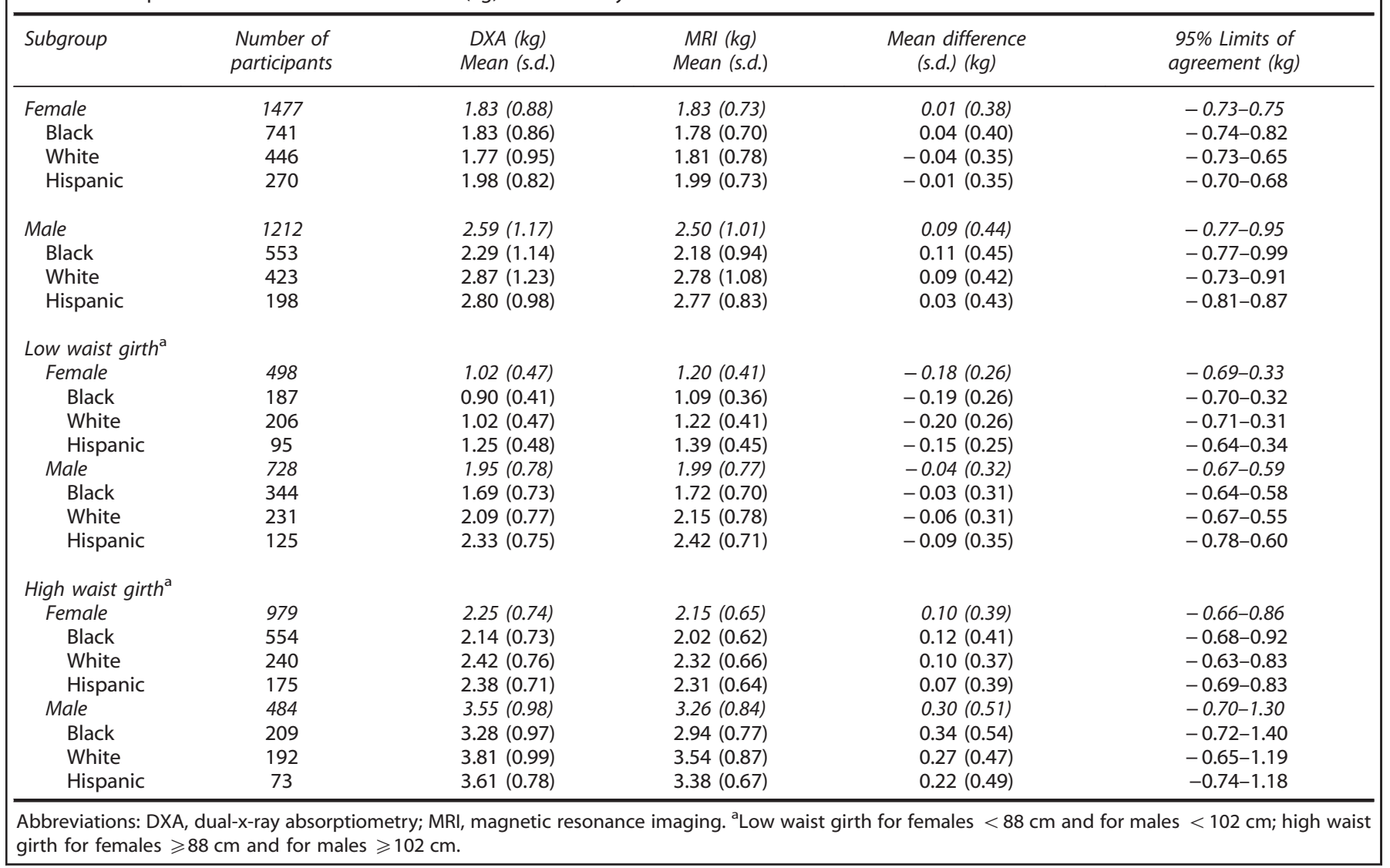


MRI-measured VAT among normal weight individuals and overestimate MRI VAT among overweight or obese individuals, especially at very high levels of VAT. However, the mean difference between methods was $0.01 \mathrm{~kg}$ for females and $0.09 \mathrm{~kg}$ for males, both small relative to the mean VAT observed
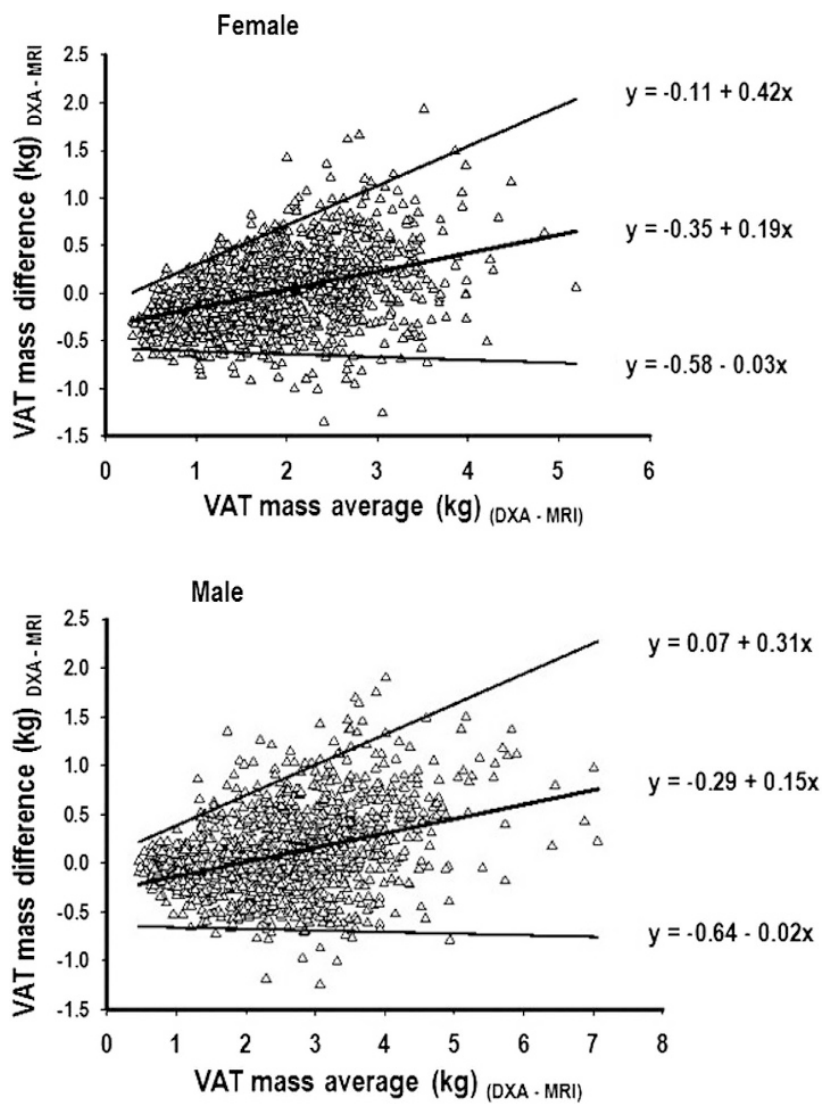

Figure 3. Bland-Altman analysis of agreement for VAT mass measured by DXA and MRI. Bland-Altman analysis using regression-based limits of agreement for the difference in VAT $(\mathrm{kg})$ determined by DXA and MRI methods. in our cohort ( 1.83 and $2.59 \mathrm{~kg}$, respectively), and considerably less than the generally agreed upon consensus of a clinically meaningful weight difference of $5 \%{ }^{23}$ Further studies are needed to assess the threshold of VAT mass changes that are clinically significant in relation to cardiovascular and metabolic risk. Results were unbiasedly validated and the model was found to be well calibrated using bootstrapping techniques. Finally, inter-individual reader variability was verified to be negligible, suggesting excellent potential for the use of DXA for VAT estimation in future clinical and research applications among across a broad spectrum of populations and across multiple readers using this software.

CT or MRI are standard tools for visceral fat quantification but are suboptimal for clinical or longitudinal research use due to high radiation exposure (with $\mathrm{CT}$ ), time-consuming image acquisition and analysis, and the need for costly, specialized equipment. DXAbased quantification of VAT has been developed as a solution and addresses many of the limitations of CT or MRI-based assessments. VAT mass measurement by DXA has been validated against CT in several smaller studies using both Hologic ${ }^{11,24}$ and $\mathrm{GE}^{10}$ scanners. These studies reported very good agreement between the two methods with $R^{2}$ values ranging between 0.865 and 0.957 . However, the sample populations were relatively homogeneous ( $>90 \%$ white in one study and all females $<49$ years old in two others) and no validation against MRI-based methods was performed. The current study directly addresses these knowledge gaps and contributes a comprehensive evaluation of the applicability and validity of using DXA to estimate VAT mass for large-scale, population-based studies.

Visceral adiposity is recognized as an important risk factor for cardiometabolic disease and may be superior to anthropometric indices of obesity (such as BMI or waist circumference) for discrimination of diabetes and cardiovascular disease risk. ${ }^{1,3}$ VAT mass measured by DXA has been shown to be associated with multiple cardiometabolic risk factors such as hypertension, diabetes and metabolic syndrome, independent of BMI and waist circumference in cross-sectional analyses, ${ }^{25}$ consistent with similar findings when VAT mass is measured by MRI. ${ }^{26}$ Our results confirm that DXA-derived VAT mass is positively associated with an adverse cardiometabolic profile and serve to internally validate the DXA VAT measurement in our study population. Whether DXA VAT methods may be employed for longitudinal assessment of VAT and its relation to cardiometabolic outcomes, remains to be

Table 5. Clinical and laboratory characteristics by DXA VAT mass quartiles

\begin{tabular}{|c|c|c|c|c|c|c|c|c|}
\hline \multirow[t]{3}{*}{ Baseline characteristics } & \multicolumn{4}{|c|}{ Female } & \multicolumn{4}{|c|}{ Male } \\
\hline & Q1 & Q2 & Q3 & Q4 & Q1 & Q2 & Q3 & Q4 \\
\hline & $(n=369)$ & $(n=370)$ & $(n=369)$ & $(n=369)$ & $(n=303)$ & $(n=303)$ & $(n=303)$ & $(n=302)$ \\
\hline DXA VAT mass range $(\mathrm{kg})$ & $0.03-1.17$ & $1.18-1.76$ & $1.77-2.46$ & $2.47-5.22$ & $0.42-1.73$ & $1.74-2.49$ & $2.50-3.32$ & $3.33-7.49$ \\
\hline Age (years) & $40.0(9.5)$ & $43.6(9.3)^{\mathrm{a}}$ & $45.8(9.8)^{\mathrm{a}}$ & $48.3(9.5)^{\mathrm{a}}$ & $41.2(9.5)$ & $43.1(9.5)^{\mathrm{a}}$ & $44.6(8.9)^{\mathrm{a}}$ & $48.4(9.4)^{a}$ \\
\hline \multicolumn{9}{|l|}{ Race (\%) } \\
\hline Black & 48.2 & $52.7^{\mathrm{a}}$ & $50.9^{\mathrm{a}}$ & $48.8^{\mathrm{a}}$ & 64.7 & $46.2^{\mathrm{a}}$ & $39.6^{\mathrm{a}}$ & $32.0^{\mathrm{a}}$ \\
\hline White & 39 & 25.4 & 26.6 & 29.8 & 26.1 & 30.7 & 36.9 & 45.9 \\
\hline Hispanic & 10.6 & 21.3 & 20.6 & 20.6 & 7.6 & 18.8 & 19.8 & 19.1 \\
\hline Body mass index $\left(\mathrm{kg} \mathrm{m}^{-2}\right)$ & $23.9(4.3)$ & $28.8(4.7)^{a}$ & $32.6(5.8)^{\mathrm{a}}$ & $37.8(6.1)^{\mathrm{a}}$ & $23.7(3.2)$ & $27.2(3.5)^{\mathrm{a}}$ & $29.8(3.4)^{\mathrm{a}}$ & $32.9(3.8)^{\mathrm{a}}$ \\
\hline Hypertension (\%) & 14.4 & $25.4^{\mathrm{a}}$ & $38.2^{\mathrm{a}}$ & $49.6^{\mathrm{a}}$ & 11.9 & $22.4^{\mathrm{a}}$ & $33.3^{\mathrm{a}}$ & $46.9^{\mathrm{a}}$ \\
\hline Diabetes (\%) & 2.2 & $4.9^{\mathrm{a}}$ & $11.9^{\mathrm{a}}$ & $21.9^{\mathrm{a}}$ & 3.9 & $7.3^{\mathrm{a}}$ & $10.9^{\mathrm{a}}$ & $18.8^{\mathrm{a}}$ \\
\hline Metabolic syndrome (\%) & 5.7 & $25.4^{\mathrm{a}}$ & $47.2^{\mathrm{a}}$ & $68.3^{\mathrm{a}}$ & 3.6 & $14.9^{\mathrm{a}}$ & $34.6^{\mathrm{a}}$ & $63.7^{\mathrm{a}}$ \\
\hline DXA fat mass $(\mathrm{kg})$ & $21.7(7.4)$ & $30.7(7.5)^{\mathrm{a}}$ & $37.1(9.5)^{\mathrm{a}}$ & $45.7(10.1)^{\mathrm{a}}$ & $14.9(4.9)$ & $22.3(5.2)^{\mathrm{a}}$ & $27.1(5.7)^{\mathrm{a}}$ & $33.5(7.2)^{a}$ \\
\hline DXA body fat (\%) & $34.4(5.9)$ & $41.1(4.1)^{\mathrm{a}}$ & $44.1(4.0)^{\mathrm{a}}$ & $46.8(4.2)^{\mathrm{a}}$ & $20.7(4.7)$ & $27.2(3.8)^{\mathrm{a}}$ & $30.1(3.9)^{\mathrm{a}}$ & $33.9(3.8)^{a}$ \\
\hline DXA lean mass $(\mathrm{kg})$ & $40.0(5.9)$ & $43.4(6.5)^{\mathrm{a}}$ & $46.3(7.4)^{\mathrm{a}}$ & $51.3(7.7)^{\mathrm{a}}$ & $56.1(7.5)$ & $59.5(8.5)^{\mathrm{a}}$ & $62.4(8.0)^{\mathrm{a}}$ & $66.1(8.5)^{\mathrm{a}}$ \\
\hline MRI VAT mass $(\mathrm{kg})$ & $1.02(0.28)$ & $1.56(0.30)^{\mathrm{a}}$ & $2.02(0.37)^{\mathrm{a}}$ & $2.72(0.53)^{\mathrm{a}}$ & $1.31(0.42)$ & $2.17(0.39)^{\mathrm{a}}$ & $2.81(0.45)^{\mathrm{a}}$ & $3.69(0.73)^{a}$ \\
\hline
\end{tabular}

Abbreviations: DXA, dual-x-ray absorptiometry; VAT, visceral adipose tissue. ${ }^{a} P<0.0001 ; P$-trend analyzed by Jonckheere-Terpstra test for continuous variables and Cochran-Armitage test for categorical variables. Q, quartile data are reported as mean (s.d.) or proportion (\%) as appropriate. 
determined. Since DXA methodology is ideal for situations requiring repeated scans over time, prospective studies including repeat measures of VAT in an observational manner or after an intervention are needed to better understand the role of DXA VAT assessment over long-term follow up.

Strengths of our study include the largest sample size for DXA VAT validation and inclusion of a cohort with large representative samples of both sexes, multiple races/ethnicities and a wide range of BMIs. Several limitations of our study also merit comment. First, we did not include participants $>65$ years or $<30$ years of age so we are unable to validate the DXA VAT method among individuals at the extremes of age. Second, since we did not repeat DXA scans with complete repositioning of the subject between scans, we are unable to measure the precision and repeatability of the DXA VAT method that may be important in assessing changes in DXA VAT longitudinally. Third, although we used robust bootstrapping techniques to validate our findings, repeat evaluation in a second large, multiethnic cohort would be ideal to fully validate the DXA VAT method for generalizable use. Fourth, as the study design is cross-sectional, we are unable to compare the accuracy of the DXA and MRI techniques for monitoring the impact of interventions targeting VAT.

\section{CONCLUSION}

In conclusion, we found that a novel DXA method of VAT mass quantification was both accurate and valid compared with MRI as the primary standard among a large, multiethnic cohort of individuals with a wide range of BMls. Our findings help to substantiate its potential use for clinical and research applications, although further studies including repeat assessments over time are needed to determine its long-term applicability.

\section{CONFLICT OF INTEREST}

The authors declare no conflict of interest.

\section{ACKNOWLEDGEMENTS}

We gratefully acknowledge the excellent support and contributions of the Dallas Heart Study Investigators and the Dallas community during the conduct of the study. The Dallas Heart Study was supported by a grant from the Reynolds Foundation and grant UL1TR001105 from the National Center for Advancing Translational Sciences of the National Institutes of Health. IJN is supported by grant K23DK106520 from the National Institute of Diabetes and Digestive and Kidney Diseases of the National Institute of Health and by the Dedman Family Scholarship in Clinical Care from UT Southwestern. SMG and GLV had partial support from the UT Southwestern Foundation and Perot Foundation.

\section{REFERENCES}

1 Neeland IJ, Turer AT, Ayers CR, Powell-Wiley TM, Vega GL, Farzaneh-Far R et al. Dysfunctional adiposity and the risk of prediabetes and type 2 diabetes in obese adults. JAMA 2012; 308: 1150-1159.

2 Chandra A, Neeland IJ, Berry JD, Ayers CR, Rohatgi A, Das SR et al. The relationship of body mass and fat distribution with incident hypertension: observations from the Dallas Heart Study. J Am Coll Cardiol 2014; 64: 997-1002.

3 Neeland IJ, Turer AT, Ayers CR, Berry JD, Rohatgi A, Das SR et al. Body fat distribution and incident cardiovascular disease in obese adults. $J$ Am Coll Cardiol 2015; 65: 2150-2151.

4 Britton KA, Massaro JM, Murabito JM, Kreger BE, Hoffmann U, Fox CS. Body fat distribution, incident cardiovascular disease, cancer, and all-cause mortality. J Am Coll Cardiol 2013; 62: 921-925.

5 Chaston TB, Dixon JB. Factors associated with percent change in visceral versus subcutaneous abdominal fat during weight loss: findings from a systematic review. Int J Obes (Lond) 2008; 32: 619-628.

6 Astrup A, Carraro R, Finer N, Harper A, Kunesova M, Lean ME et al. Safety, tolerability and sustained weight loss over 2 years with the once-daily human GLP-1 analog, liraglutide. Int J Obes (Lond) 2012; 36: 843-854.

7 Gaborit B, Jacquier A, Kober F, Abdesselam I, Cuisset T, Boullu-Ciocca S et al. Effects of bariatric surgery on cardiac ectopic fat: lesser decrease in epicardial fat compared to visceral fat loss and no change in myocardial triglyceride content. $J$ Am Coll Cardiol 2012; 60: 1381-1389.

8 Laskey MA. Dual-energy X-ray absorptiometry and body composition. Nutrition 1996; 12: 45-51.

9 Blake GM, Naeem M, Boutros M. Comparison of effective dose to children and adults from dual X-ray absorptiometry examinations. Bone 2006; 38: 935-942.

10 Kaul S, Rothney MP, Peters DM, Wacker WK, Davis CE, Shapiro MD et al. Dualenergy X-ray absorptiometry for quantification of visceral fat. Obesity (Silver Spring) 2012; 20: 1313-1318.

11 Micklesfield LK, Goedecke JH, Punyanitya M, Wilson KE, Kelly TL. Dual-energy $\mathrm{X}$-ray performs as well as clinical computed tomography for the measurement of visceral fat. Obesity (Silver Spring) 2012; 20: 1109-1114.

12 Choi YJ, Seo YK, Lee EJ, Chung YS. Quantification of visceral fat using dual-energy $x$-ray absorptiometry and its reliability according to the amount of visceral fat in Korean adults. J Clin Densitom 2015; 18: 192-197.

13 Lin H, Yan H, Rao S, Xia M, Zhou Q, Xu H et al. Quantification of visceral adipose tissue using lunar dual-energy $\mathrm{X}$-ray absorptiometry in Asian Chinese. Obesity (Silver Spring) 2013; 21: 2112-2117.

14 Victor RG, Haley RW, Willett DL, Peshock RM, Vaeth PC, Leonard D et al. The Dallas Heart Study: a population-based probability sample for the multidisciplinary study of ethnic differences in cardiovascular health. Am J Cardiol 2004; 93: 1473-1480.

15 Vega GL, Adams-Huet B, Peshock R, Willett D, Shah B, Grundy SM. Influence of body fat content and distribution on variation in metabolic risk. J Clin Endocrinol Metab 2006; 91: 4459-4466.

16 Deo R, Khera A, McGuire DK, Murphy SA, Meo Neto Jde P, Morrow DA et al. Association among plasma levels of monocyte chemoattractant protein-1, traditional cardiovascular risk factors, and subclinical atherosclerosis. J Am Coll Cardiol 2004; 44: 1812-1818.

17 Grundy SM, Cleeman J, Daniels SR, Donato KA, Eckel RH, Franklin BA et al. Diagnosis and management of the metabolic syndrome: an American Heart Association/National Heart, Lung, and Blood Institute Scientific Statement. Circulation 2005; 112: 2735-2752.

18 Abate N, Garg A, Coleman R, Grundy SM, Peshock RM. Prediction of total subcutaneous abdominal, intraperitoneal, and retroperitoneal adipose tissue masses in men by a single axial magnetic resonance imaging slice. Am J Clin Nutr 1997; 65: 403-408.

19 Bland JM, Altman DG. Measuring agreement in method comparison studies. Stat Methods Med Res 1999; 8: 135-160.

20 Harrell FE Jr., Lee KL, Mark DB. Multivariable prognostic models: issues in developing models, evaluating assumptions and adequacy, and measuring and reducing errors. Stat Med 1996; 15: 361-387.

21 Ivanescu AE, Li P, George B, Brown AW, Keith SW, Raju D et al. The importance of prediction model validation and assessment in obesity and nutrition research. Int J Obes (Lond) 2015; 40: 887-894.

22 Landis JR, Koch GG. The measurement of observer agreement for categorical data. Biometrics 1977; 33: 159-174.

23 Jensen MD, Ryan DH, Apovian CM, Ard JD, Comuzzie AG, Donato KA et al. AHA/ACC/TOS guideline for the management of overweight and obesity in adults: a report of the American College of Cardiology/American Heart Association Task Force on Practice Guidelines and The Obesity Society. Circulation 2014; 129 (25 Suppl 2): S102-S138.

24 Bredella MA, Gill CM, Keating LK, Torriani M, Anderson EJ, Punyanitya M et al. Assessment of abdominal fat compartments using DXA in premenopausal women from anorexia nervosa to morbid obesity. Obesity (Silver Spring) 2013; 21: 2458-2464.

25 Rothney MP, Catapano AL, Xia J, Wacker WK, Tidone C, Grigore L et al. Abdominal visceral fat measurement using dual-energy X-ray: association with cardiometabolic risk factors. Obesity (Silver Spring) 2013; 21: 1798-1802.

26 Neeland IJ, Ayers CR, Rohatgi AK, Turer AT, Berry JD, Das SR et al. Associations of visceral and abdominal subcutaneous adipose tissue with markers of cardiac and metabolic risk in obese adults. Obesity (Silver Spring) 2013; 21: E439-E447.

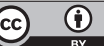

This work is licensed under a Creative Commons Attribution 4.0 International License. The images or other third party material in this article are included in the article's Creative Commons license, unless indicated otherwise in the credit line; if the material is not included under the Creative Commons license, users will need to obtain permission from the license holder to reproduce the material. To view a copy of this license, visit http://creativecommons.org/licenses/ by/4.0/

(c) The Author(s) 2016 